\title{
Uncertainty, social norms and consumption theory: Post and New Keynesian approaches
}

\author{
Jan-Oliver Menz
}

\begin{abstract}
Consumption theory has always been a neglected field in post-Keynesian economics, whereas it is at the center of New Keynesian economics. This paper investigates similarities and differences between the two approaches. I will show that the newer mainstream models indeed give results that are fairly similar to traditional Keynesian ideas, even if differences - especially concerning methodological questions - still remain. Building on insights from Economic Sociology and Behavioral Economics, the importance for consumption theory of an adequate treatment of risk and uncertainty on the one hand, and the role of social norms on the other hand are emphasized.
\end{abstract}

JEL classifications: E2I, EI2, DII

Keywords: uncertainty, social norms, consumption theory, post-Keynesianism, New Keynesianism

"There are known knowns. There are things we know that we know. There are known unknowns. That is to say, there are things that we now know we don't know. But there are also unknown unknowns. There are things we do not know we don't know."

Donald Rumsfeld ${ }^{\mathrm{T}}$

Press Conference at NATO Headquarters, Brussels, Belgium, June 6, 2002.

* University of Hamburg. I am thankful to Eckhard Hein, Ulrich Fritsche, Lena Vogel, Malachi McIntosh, Kai Friemel, Ben Jacoby, Irem Sentürk and two anonymous referees for helpful suggestions and clarifying discussions. Remaining errors are of course mine.

Correspondence Address:

Jan-Oliver Menz, Faculty Economics and Social Sciences, University of Hamburg, Germany, e-mail: Jan-Oliver.Menz@wiso.uni-hamburg.de.

Received oI July 2008, accepted to March 2009

(C) INTERVENTION 7 (I), 20IO, I25-I46 


\section{Introduction}

This paper deals with consumption theory using a paradigmatic approach to establish similarities and differences between New Keynesian and post-Keynesian theories. I distinguish these two approaches by their treatment of risk and uncertainty, and their use of optimizing microeconomic tools. ${ }^{2}$ The paper tries to shed light on two main questions: Against the background of the New Consensus Model in macroeconomics, does there also exist a unifying approach to consumption theory today? And if so, what are its characteristics? Is this new consumption theory just a least common denominator, or can one find some agreement with more fundamental Keynesian theories?

I will start with a detailed discussion of the different interpretations of risk and uncertainty in the literature. A wide range of different approaches have been presented recently which investigate the gray area between Keynes's concept of fundamental uncertainty, and the neoclassical assumption of quantifiable risk (Section 2.I). I will then evaluate the implications of a more sociologically based consumption theory (Section 2.2). Besides the rejection of rational expectations by post-Keynesians but also by some New Keynesian authors, it is neither clear what follows from this rejection, nor how to formalize an alternative expectations theory. Section 2.3 discusses some implications of this critique for consumers' expectations and decision process. Since both the topic of decisions under risk and uncertainty, and the role of social norms are important parts of Behavioral Economics (Camerer et al. 2003), I will make extensive use of this approach. In the two following parts, I will present both a New Keynesian and a post-Keynesian consumption model in order to exemplify the consequences of the previous theoretical discussion. For the New Keynesian approach (Section 3), I have chosen the precautionary saving model (Carroll/Kimball 2008), since this has re-introduced the importance of an adequate treatment of risk and uncertainty into mainstream economics. Even if the modifications of this model are less far-reaching than other New Keynesian approaches - as for example the sticky information model (Reis 2006) - one can still show that some of its implications are similar to original Keynesian ideas. In contrast, a post-Keynesian consumption function is presented in Section 4, putting special emphasis on functional income distribution. Section 5 concludes by discussing several potential extensions of the presented models.

2 For a more detailed comparison between New Keynesian and post-Keynesian theory see Hein (2005). 


\section{Uncertainty, expectations formation and social norms}

\section{I Risk and uncertainty}

In order to understand how consumers act under uncertainty, it is useful to clarify the different definitions and interpretations of risk and uncertainty in the literature. Broadly, one can distinguish individual and sociological dimensions of uncertainty and risk.

Individual Dimensions of Uncertainty: Looking at uncertainty and risk from the perspective of a single individual, one can distinguish two further dimensions (see Figure I).

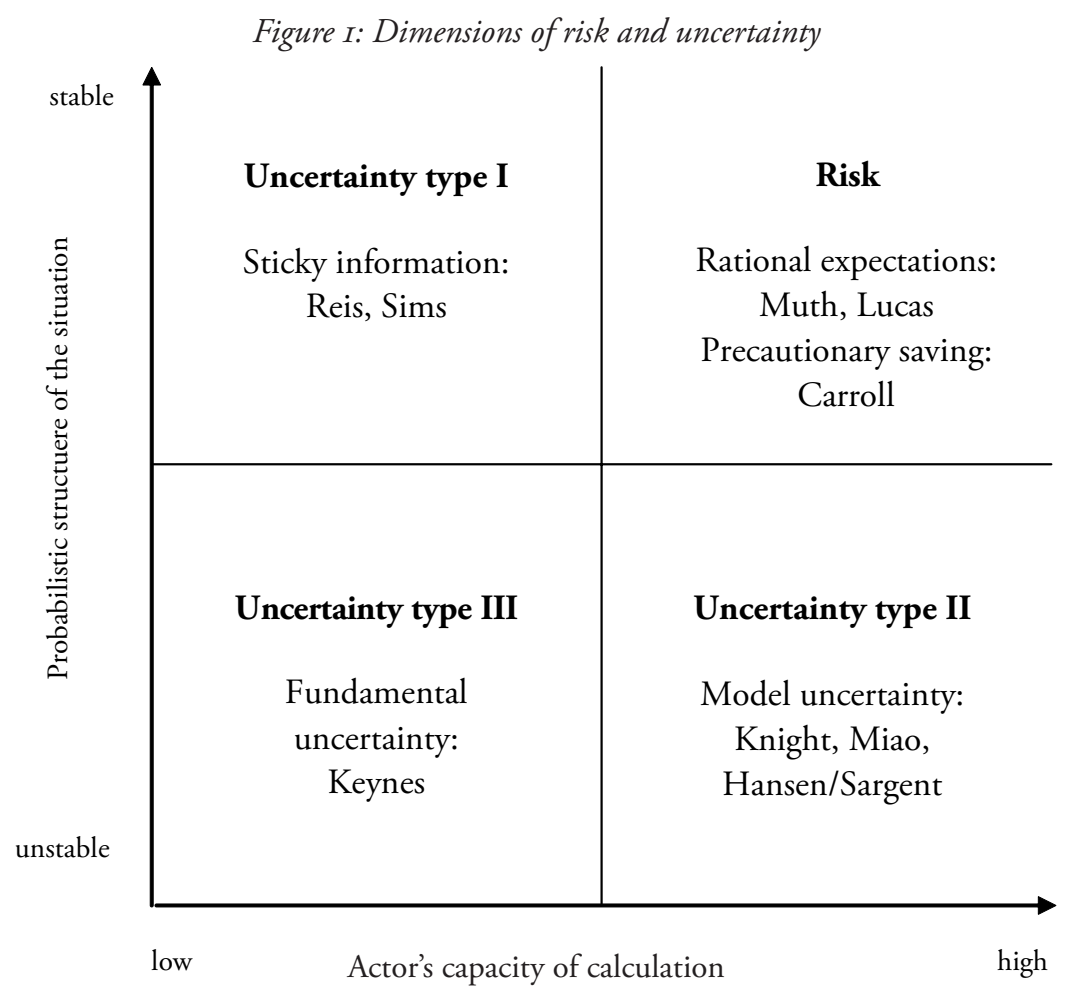

The first dimension can be called the "probability structure of the situation", which can be either stable or unstable. In Davidson's terms (I99I), this distinction can be called »ergodic" and »non-ergodic", Fontana/Gerrard (2004) call it the "aleatory dimension", and Lawson (I988), following Knight (I92I) refers to it as numerically »measurable« and »immeasurable» probability. Essentially, all these categorizations discriminate between the same dimension, namely whether the future can be described by probabilities which can be identified, measured, compared and used to calculate averages and higher moments of distributions over time. For the second dimension, one could use a distinction between two different lines: 
either where the computational capacity of the actor is assumed to be high or low, or where probabilities are assumed to be subjective or objective. The first line, which I am using in Figure I, tackles the question whether the actor has access to all the relevant information, whether this access is costless, and whether the actor is able to handle this information accordingly. I call this dimension "actor's capacity of calculation«; Fontana/Gerrard (2004) refer to it as the "epistemic « dimension. The second line is based on the argument put forward by Lawson (1988) and Hansen/Sargent (2007), namely that it is important whether probabilities are considered to be part of individual knowledge or belief - i.e. being subjective - or whether there exist objective probabilities that are part of the external reality, and are thus independent of the individual's mind and actions. I chose the dimension of the computational capacity of the actor in my graphical presentation, but I will also refer to the nature of probabilities when necessary for my argument. The different definitions of risk and uncertainty in the literature can be classified along these lines as follows:

First, neoclassical economists such as Muth (196I) and Lucas (1972) have for a long time assumed high computational capacities of economic actors, together with a known and stable probability function of all possible outcomes in the future - the case of risk in Figure I. From these assumptions stems the well-known rational expectations theory which claims that economic actors take into account future events in the present. It also implies that errors cancel out each other, i.e. expectations are unbiased, and the best forecast is the average. This is also the case with the so called diversifiable risk that only affects a certain group of people, and against which people can thus insure themselves. Rational expectations also imply that subjective probabilities equal objective ones, since all the agents are assumed to know the relevant economic model (Hansen/Sargent 2007). Still within the category of risk, but with a less restrictive approach, New Keynesians such as Carroll/Kimball (2008) have emphasized the importance of precautionary saving. The difference to previous neoclassical approaches consists of the role of the variance of future income, which becomes relevant if one relaxes the restrictive neoclassical assumption of a quadratic utility function (see in more detail below).

Second, New Keynesians have recently emphasized another direction by questioning the lack of information costs implicitly assumed by the rational expectations hypothesis. The models of sticky information (Uncertainty Type I) admit that some agents in the economy are not able to, or choose not to calculate all possible outcomes of their decisions because the process of acquiring and using information is costly (Reis 2006), or because individuals have limited information processing capacity (Sims 2003). However, this theory still assumes that one could in principle calculate the probabilities for all the possible outcomes of the decision, and that deviations and mistakes in expectation-building can be solved through learning processes. ${ }^{3}$

Third, Uncertainty Type II describes a situation in which the actor possesses full cognitive capacity of calculation, while at the same time the probabilistic structure of the situation is not stable. Thus, one could say that the agent does not know which model he 
should use in order to do his calculations, a situation which can be formalized by allowing for a set of different probability distributions among which the agent chooses. This situation is described by Knight (I92I), Miao (2004), and Hansen/Sargent (2007). Knight also claimed that probabilities are objective, i.e. even if single actors deviate from these probabilities, this is only a temporary problem, since in the long run subjective probabilities will converge to the objective ones.

Fourth, Keynes's fundamental uncertainty can be classified as Uncertainty Type III. As Keynes (I937: 2I4) put it: "The sense in which I am using the term [uncertainty] is that [...] there is no scientific basis on which to form any calculable probability whatever. We simply do not know." Generally speaking, uncertainty arises out of the gap between the complexity of a given situation and the limited cognitive capabilities of actors. Keynes also treats probabilities as being subjective (Rosser 200I, Muchlinski 1996).

Sociological Dimension of Uncertainty and Risk: If one analyzes individual behavior in its social context, another factor for explaining uncertainty and risk becomes relevant. In the view of Economic Sociology, the simple equalization of risk and uncertainty neglects two main problems:

First, it is argued that one cannot know all ımeans-ends relations in complex situations, which results in unintended side-effects and in the impossibility of behaving in the way predicted by the optimization model:

"It is not the action-model of homo economicus per se that should be the focus of criticism [...], but the underlying assumption that economic actors can, even in highly contingent situations, deduce their actions from a clear preference ranking and thereby maximize their utility." Beckert (1996: 804)

Behavioral Economists such as Kahnemann/Thaler (2006) have criticized the concept of utility maximization for a similar reason: In general, agents rarely know the outcome of their decisions influencing their future utility, thereby being subject to various errors. More precisely, the authors question the necessary assumption for utility-maximization, namely "the ability of economic agents to make accurate, or at least unbiased, forecasts of the hedonic outcomes of potential choices" Kahnemann/Thaler (2006: 222).

Post-Keynesians in the tradition of Shackle (1955) have emphasized the same point: Since the actor cannot be sure about the outcomes of his decision, he is actually creating uncertainty. Hence, decision-making cannot be described without taking into account the particularities of each situation. If the situation is highly uncertain, the agent does not know ex ante if his behavior is rational. The crucial assumption of rational behavior is that people know the links between their actions and the outcomes of their actions. The implementation of risk then only slightly complicates the situation, since one only needs to consider the probabilities that can be assigned by assumption to any possible `means-end-relation`. But in the case of uncertainty, this does not hold since the problem of the means-ends-relations is multiplied by the uncertainty about other agents' behavior. This leads to the second problem, namely that social action is characterized by a »double contingency» (Beckert 
I996: 826): Individuals not only have to consider their cognitive capacities, and the special conditions in which they have to decide, but must also take into account the behavior of at least one additional actor. Since consumers do not build up their preferences independently but with reference to their most relevant social peer group, the problem of »double contingency is crucial for consumption theory. It follows that the assumption of the representative agent is too restrictive, since it assumes this problem away completely, and neglects idiosyncratic - i.e. uninsurable - income risk (Carroll 2000).

\subsection{Social norms}

Besides the question of uncertainty and risk, a second important property of consumption behavior is its dependence on social norms:

"Consumption is the economic activity that depends most on social and cultural context and least on either formal rationality or complex technology.«Zukin (2006: IOI)

Both post-Keynesian economists and Economic Sociologists have long-held doubts about the implicit neoclassical assumption that individuals are highly independent in their consumption decisions. Consequently they downplay the importance and relevance of individual decisions, and follow an organicist methodological approach - in contrast to to the methodological individualism of Neoclassicals and New Keynesians. Methodological individualism places the individual at the center of the analysis, and claims that people are able to choose between different consumption bundles. Post-Keynesians tend to see individual's behavior as embedded in different social contexts or systems, with the latter structuring and shaping individual decisions. ${ }^{4}$ Similar to the classification of uncertainty and risk in Section 2.I, one can distinguish between an individual and a sociological dimension of social norms.

Individual Dimension of Social Norms: This line of research allows for effects of social norms on individual behavior. However, these effects are exogenous and the individual is still at the center of the analysis. This is true for the work by Akerlof (2007), who has stated that individuals are constrained in their decisions by the existence of social norms. He suggested that one should incorporate a loss term into the standard utility function that becomes relevant if the individual's decisions are not in line with the social norm for this particular behavior. ${ }^{5}$ Moreover, individuals are also constrained in their decisions by role conflicts. Since citizens in modern societies have to adopt different social roles, they have a different preference structure in each role. For example, a person can have different preferences in his role as an investment banker and as a father, leading to a role conflict which makes

4 One can also find this separated view in sociology, where the $>$ Rational Choice Theory stands in contrast to the 'Systems Theory of Luhmann (1984).

5 For example: Public opinion expects students to live in cheap apartments and not in large houses even though this would be rational in the context of neoclassical consumption smoothing. 
it impossible to construct the intransitive preference order necessary for the existence of the neoclassical consumer. Sociologists following Horkheimer/Adorno (I947: Chapter 4), and also Galbraith (1958), go even further in criticizing the neoclassical concept of the independence and sovereignty of consumers. They claim that firms influence and even manipulate consumers' decisions, which puts the firm into the center of economic analysis. Moreover, post-Keynesians such as Lavoie (I994 and 2004) have highlighted the importance of Maslow's (1943) »hierarchy of needs « for consumption behavior. In this view, individuals have different categories of needs and move with higher income levels from lower categories to higher ones.

Given two consumption bundles $x$ and $y$, this idea can be represented formally by lexicographic preferences: ${ }^{6}$

$$
x \succ y \Leftrightarrow\left\{" x_{1}>y_{1} \text { " or " } x_{1}=y_{1} \text { and } \mathrm{x}_{2} \geq y_{2} "\right\}
$$

In one category of needs, the consumer prefers more of good $x_{1}$ compared to $y_{1}$. But when he has consumed a satisfying amount of $x_{1}$, he only prefers the consumption bundle $x$ against $y$ if he can consume more from a second good, i.e. $x_{2} \geq y_{2}$. The crucial point of these lexicographic preferences is that one cannot calculate derivatives. Lexicographic preferences are perfectly transitive, complete and reflexive, thus fulfilling all conditions for rationality. The only problem is their non-representativity through the use of utility functions, which has led post-Keynesians to abandon the expected utility approach. A further important implication of this approach is that the role of the price mechanism and of substitution effects is downplayed, and income effects are upgraded. This is because people go from one category of needs to the next following an increase in income and neglecting price changes of goods in a higher category when the more fundamental one is not yet satisfied.

Sociological Dimensions of Social Norms. The theories presented so far have mostly neglected social interactions between individuals, and reduced the influence of social norms to an exogenously given constraint. Following Duesenberry (1949), people want to »keep up with the Joneses", i.e., individuals link their consumption decisions to those of their closest social reference group in order to reach or keep a similar social status; an alternative theory whose relevance has recently been highlighted again by Holländer (200I). Post-Keynesians emphasize the same point:

"Decisions and preferences are not made independently of those of other agents. A household's pattern of consumption will reflect the lifestyle of the other households that constitute its social reference group.« (Lavoie 2004: 647)

In order to take this social interaction between consumers into account and allow for socially determined needs, Trigg (2004) has argued that one should replace Maslow's (1943) justification for a post-Keynesian consumption theory with an alternative view provided by Bourdieu. Bourdieu (1979) has highlighted the link between social classes and consumption, showing not only that individual tastes are strongly determined by their class background, 
but that these different tastes are also used to ensure class reproduction. ${ }^{7}$ Thus, social norms are not simply a constraint of individuals' otherwise completely rational decisions, but they are also adopted voluntarily to express social class identity. Recently, the importance of social interaction has also gained interest within Behavioral Economics. Criticizing the habit formation model for its assumption of an exogenously given reference standard, Falk/Knell (2004) have presented a model in which individuals compare themselves to similar others, and thus determine their reference standard endogenously.

\subsection{The implications for expectation formation and consumption behavior}

Having discussed the general principals of consumers' decision making, it is important to evaluate carefully their implications for individuals' expectation formation. As I have already mentioned, under the assumption of pure risk, individuals use rational expectations. However, even if this concept seems formally appealing, there has emerged a wide literature criticizing its use, either for the lack of empirical evidence (Rudd/Whelan 2006), for the absence of systematic error in rational expectations (Caplan 2007), or for theoretical inconsistencies (Gertchev 2007).

From a New Keynesian Perspective, some of these critiques have been used to formulate refinements of expectation formation. First, the precautionary saving model put forward by Carroll (200I) and Carroll/Kimball (2008) stays closest in its assumption to the neoclassical rational expectation model. However, the authors already show that by relaxing the assumption of a quadratic utility function, not only the expected value but also the variance of future variables becomes relevant. The implications of this will be shown in more detail below. Besides this, two further directions seeking to refine rational expectations have emerged. Under Uncertainty Type I, the existence of information costs makes a fraction of individuals ignore new information, and thus act on the basis of their old information set. ${ }^{8}$ Under Uncertainty Type II, individuals do not know the correct model, and are thus also uncertain about the correct probabilities. Following Miao (2004), I will later sketch an extension of the precautionary saving model that formulates this idea.

Furthermore, approaches that follow the idea of Uncertainty Type III more closely - i.e. Keynesian fundamental uncertainty - have evaluated three possible implications for expectation formation:

First, post-Keynesians such as Davidson (I99I), or Neoclassicals such as Lucas, defending the use of rational expectations, seem prone to the idea that in the case of uncertainty, one cannot say anything about the individual's behavior: "In case of uncertainty, economic reasoning will be of no value. " ${ }^{9}$ This interpretation might be based on the famous »Wesimply-do-not-know« quote by Keynes.

7 See also Beckert (1996: 827 - 830) for the link between the determination of the relevant social reference group and their belonging to a specific social class.

8 Caplan (2007) calls this "rational ignorance".

9 Lucas, as quoted by Gertchev (2007: 320). 
A second direction uses adaptive expectations, implying that individuals are purely backward-looking. The use of this practice can be attributed to Keynes, who had claimed that investors assume » that the existing state of affairs will continue indefinitely, except in so far as we have specific reasons to expect a change." (Keynes 1936: I52) However, as Gertchev (2007) has recently re-emphasized, adaptive expectations have several drawbacks: Since individuals are assumed to simply extrapolate the past, there is neither an autonomous role for expectations about the future, nor do individuals learn in case they had been fooled in the past. Models with learning individuals have been developed in order to overcome this criticism. $^{\text {Io }}$

A third direction highlights individuals' orientation on social norms, rule of thumbs, or experts' opinion when having to take a decision under fundamental uncertainty. Keynes also provides evidence for this interpretation:

"Knowing that our own individual judgment is worthless, we endeavor to fall back on the judgment of the rest of the world which is perhaps better informed." (Keynes 1937: 214)

Following this approach, and in clear contrast to the nihilistic position of Lucas, Heiner (1983) states that especially in situations of fundamental uncertainty, individual behavior becomes predictable, thus enabling researchers to analyze the resulting patterns of behavior. The importance of social norms becomes especially important under the ssociological dimension of uncertainty. In this case, individuals try to implement social structures to overcome their uncertainty about the behavior of other agents, and to make it more predictable, thus shaping the situation with which each actor is confronted: Agents

"rely on social devices that restrict their flexibility and create a rigidity in the responses to changes in an uncertain environment« (Beckert I996: 819).

The existence and the need for social norms and institutions can thus also be derived directly from decision theory. The higher the degree of uncertainty in one situation, the higher the likelihood that the agent deviates from rational behavior and has trust in "all form of rules, social norms, conventions, institutions, social structures, and power-relations. " (Beckert 1996: 820) Hence, the orientation on social norms is not resulting from the need to express social identity, but is a self-imposed restriction to deal with the unknown outcomes of the individual's own decisions. Obviously, this interpretation implies the use of game theory. Beckert (1996) has denied that game theory is of great use tackling this problem since it postulates that both agents behave rationally in judging the other player's behavior. But recently, Behavioral Economists (e.g. Sobel 2005, Geanakoplos et al. 1989) have developed the concept of psychological game theory, which seems to be more appropriate for dealing with situations of double contingency.

It remains to evaluate which rules are adopted. In the case of consumption decision, two kinds of rules are important. One can be termed as ssocial learning , i.e. people learn 
about their own preferences by observing the behavior of members of their own social peer group (Glaeser et al. 2003). A second set of rules are sspending rules`. It is from this second set of rules that one can derive the importance of functional income distribution for consumption behavior. Neoclassical economists had assumed that there only exists one single category of wealth. However, Behavioral Economists such as Shefrin/Thaler (I988) criticize this assumption with their concept of "mental accounting «: They state that people are characterized by inner conflicts. In the case of consumption this signifies that there exists a confrontation between the urge to consume as much as possible today, and the wish to save for retirement. To find a solution to this problem people can either exert self-control through will-power at the moment when the conflict arises, or impose constraints on their income and consumption in advance. People prefer the second possibility because it is less costly, due to its pre-commitment character. The most important self-imposed constraints are mental accounts: People are not indifferent between different income types, but divide their wealth into three components, namely current income, current assets and future income. Each income class is treated in a unique way: Consumers finance an increase in consumption first out of their current income, then out of their current assets, and then out of future income. Note as well, that these three income accounts can be distinguished by their degree of uncertainty, thus providing further support for a high marginal propensity to consume (MPC) out of current labor income. Also, New Keynesians such as Galí et al. (2007) have recently used rule of thumbs for explaining consumption behavior. Without providing a microeconomic explanation, they assume that workers spend all their current labor income in every period, while other agents follow the standard inter-temporal optimization approach. Post-Keynesians have always emphasized the importance of functional income distribution, however, for completely different reasons. They either follow Marx by using a model consisting of two classes, workers and capitalists, or Kaldor by arguing that most of firms' profits are retained in the firm, implying a higher saving rate out of profits than out of wages (Hein 2004).

Finally, it is worth noting that one important dimension of expectation formation has not yet been dealt with extensively in the literature, namely whether consumers and firms form expectations in the same way. Whereas this has been assumed by the sticky information models following Reis (2006), Keynes (1936) suggested that fundamental uncertainty mainly affects long-run firm behavior, and that consumers behave more in line with a standard risk, i.e. rational expectations framework.

Concerning the implications of social norms for consumption behavior, one clearly observes important intersections with the effects of uncertainty and risk. Individuals use rule of thumbs both to cope with uncertainty, and to express their social identity by showing their belonging to a specific social peer group. They also refrain from using an optimization framework in order not to violate social norms. To quote two examples from Behavioral Economists: Akerlof (2007: I3 - 18) summarizes empirical evidence showing that the crucial consumption norm is simply that people should spend what they earn and not smooth consumption when they know about a heritage in the near future; whereas Carroll (2006) has postulated that for a part of the population, wealth enters directly into the util- 
ity function, which means that the rich part of capitalist societies saves large sums of money just for the sake of accumulation. As discussed earlier, this perspective upgrades the importance of income effects and social interaction, and downgrades the role of substitution and price effects. In the next sections, I will present in more detail how uncertainty and risk have been treated in New and post-Keynesian consumption models.

\section{Risk in New Keynesian consumption theory: Precautionary saving}

\section{I Neoclassicals and New Keynesians}

As Keynes (1936: 96) stated in his General Theory: »Men increase their consumption as income increases, but not by as much as the increase in income. "Thus, individuals are supposed to rely mainly on current income when deciding what, and how much to consume. Neoclassical economists have heavily criticized this thesis, not least due to its non-derivation from optimal microeconomic behavior. ${ }^{\text {II }}$ Friedman (I957) replaced current income with "permanent income«, supposing that consumers regard mainly their expected future income, while Modigliani/Brumbergh (1954) showed that individuals try to smooth their consumption over their entire lifetime. These neoclassical criticisms changed the main Keynesian consumption hypothesis into the contrary of its traditional results: First, consumption does not depend on current disposable income, but on the expected permanent lifetime income. Second, the MPC out of current income is not close to one, but much lower, since individuals only consume if they consider income changes as permanent. And third, the consumption function loses its concavity, i.e., an increase in income does not lead to a decline in the marginal propensity to consume.

Recently, New Keynesians, while fully adopting the neoclassical `Life-Cycle-Permanent-Income-Hypothesis framework, have relaxed some of its assumptions. The idea consists mainly of imposing restrictions which prevent the consumer from behaving fully rational, with the different treatment of risk as the prominent example. ${ }^{\mathrm{I2}}$ Criticizing the implicit assumption made by Friedman and others that households have perfect knowledge about their future income, Hall (1978) was the first to pay greater attention to the role of risk when considering explicitly the impact of the use of rational expectations in a standard neoclassical consumption model. However, his `Certainty Equivalence Approach ‘ consisted mainly of treating uncertainty by simply assuming the problem away. Hall used a quadratic utility function which has several drawbacks: Without a third derivation, only the average and not the variance of future income is included in the consumption function, hence one treats uncertainty as if it were not there. ${ }^{13}$

II See Carroll (200I) for an overview of the historical development in consumer theory.

I2 Other features trying to explain departures from the Life-Cycle-Model are credit restrictions and myopia.

I3 See for an early criticism of this approach Blanchard/Mankiw (1988), and Größl/Fritsche (2007) for a model that explicitly deals with this problem. 
The New Keynesian theory of precautionary saving departed exactly at this point, namely in criticizing Hall's use of the specific quadratic utility function through which risk drops out during the optimization process. In what follows, I will demonstrate the precautionary saving theory using a simple two-period-model. This allows for both a more adequate treatment of risk, and an explanation of the high significance of current income in many empirical studies, which always stood in contrast to the mainstream consumption model. ${ }^{\mathrm{I}}$

\subsection{The model}

Defining precautionary saving as the "additional saving that results from the knowledge that the future is uncertain " (Carroll/Kimball 2008: 2), the precautionary saving model can be derived as follows: ${ }^{15}$ The household gets utility from consumption $C$ in period $t$ and in period $t+1$, where the latter is uncertain because the household does not know for sure how much it will earn in the next period, and where the discount factor $\beta$ measures the household's preference for utility in the present and in the future.

$$
U=-\frac{1}{\eta} e^{-\eta C_{t}}+\beta E_{t}\left[-\frac{1}{\eta} e^{-\eta C_{t+1}}\right]
$$

Remember the interpretation of risk in this framework. The use of the expectations operator assumes implicitly that the agent knows the probability distribution of all his possible future income streams, and thus the agent looks at the average income being calculated on his income received in the past. The difference from the older neoclassical model lies in the definition of risk: While Hall treated risk only as diversifiable, and thus $\eta$ as the coefficient of risk aversion defined as $-\frac{u^{\prime \prime}(Y)}{u^{\prime}(Y)}$, New Keynesians included additionally non-diversifiable risk reinterpreting $\eta$ as the coefficient of prudence aversion, defined as $-\frac{u^{\prime \prime \prime}(Y)}{u^{\prime \prime}(Y)}$. Hence it follows the obvious importance that the third derivative of the utility function exists. ${ }^{16}$ This distinction is crucial: While diversifiable risk can be reduced using appropriate insurance and financial market instruments, this is not the case for systemic or non-diversifiable risk. The consumer maximizes this utility function subject to his intertemporal budget constraint:

$$
C_{t+1}=\tilde{Y}_{t+1}+R_{t}\left(Y_{t}-C_{t}\right)
$$

I4 See e.g. Campbell/Mankiw (1989) or Akerlof (2007: I4) for brief overviews of the empirical evidence. These studies also point out that credit restrictions or myopia can only partly explain real consumption behavior.

I5 This section borrows from Miao (2004). I also use a constant absolute risk aversion (CARA) utility-function instead of the more common constant relative risk aversion (CRRA) function to be able to derive the results analytically.

I6 See for this in detail Kimball (1990). 
Here, $R_{t}$ stands for the real interest rate and the tilde above the income $\tilde{Y}_{t+1}$ in the second period signals that this income is risky. Thus, the household can consume in period $t+1$ what he has saved in period $t, R_{t}\left(Y_{t}-C_{t}\right)$, and what he will probably earn in period $t+1$.

Putting this in the utility function (2) yields

$$
U=-\frac{1}{\eta} e^{-\eta C_{t}}-\beta \frac{1}{\eta} e^{-\eta R_{t}\left(Y_{t}-C_{t}\right)} E_{t}\left[e^{-\eta \tilde{Y}_{t+1}}\right]
$$

To get the optimality condition, one must derive the first order condition:

$$
e^{-\eta C_{t}}=\beta R_{t} e^{-\eta R_{t}\left(Y_{t}-C_{t}\right)} E_{t}\left[e^{-\eta \tilde{Y}_{Y+1}}\right]
$$

If one solves ( 5 ) for $C_{t}$, one gets optimal consumption as:

$$
C_{t}=\frac{R_{t}}{1+R_{t}} Y_{t}-\frac{1}{\eta\left(1+R_{t}\right)} \ln R_{t} \beta-\frac{1}{\eta\left(1-R_{t}\right)} \ln E_{t}\left[e^{-\eta \tilde{Y}_{t+1}}\right]
$$

To specify this result further, one can make the assumption that the stochastic term in the expectations operator can be described by a normal distribution. Hence one can reformulate the stochastic term with $\mu_{Y}$ as expected value, and $\sigma_{Y}^{2}$ as variance of the future income:

$$
\ln E_{t}\left[e^{-\eta \tilde{Y}_{t+1}}\right]=-\eta \mu_{Y}+\frac{1}{2} \eta^{2} \sigma_{Y}^{2}
$$

Using this, one obtains for the optimal consumption rule

$$
C_{t}=\frac{R_{t}}{\left(1+R_{t}\right)} Y_{t}-\frac{1}{\eta\left(1+R_{t}\right)} \ln R_{t} \beta-\frac{1}{\eta\left(1+R_{t}\right)}\left[-\eta \mu_{Y}+\frac{1}{2} \eta^{2} \sigma_{Y}^{2}\right]
$$

and, after a short manipulation,

$$
C_{t}=\frac{R_{t}}{\left(1+R_{t}\right)}\left(Y_{t}+\mu_{Y}\right)-\frac{1}{\eta\left(1+R_{t}\right)} \ln R_{t} \beta-\frac{1}{\left(1+R_{t}\right)} \frac{1}{2} \eta^{2} \sigma_{Y}^{2}
$$

This expression shows the key features of the precautionary saving model: First, consumption depends not only on the current income, but also on the expected life-time income. The consumer will spend a large amount of an income increase on consumption only if he considers this increase to be permanent, i.e., only if it augments the expected average income. Otherwise, if the consumer expects his life-time income to be stable or even falling, an increase in current income has less impact on consumption, i.e., the marginal propensity to consume is lower than suggested in traditional Keynesian approaches. Second, New Keynesian models contain an additional variance term in the consumption function which leads in turn to a higher MPC: Since households cannot be sure about their future income, they keep a buffer-stock of savings in order to insure themselves against unforeseeable income shocks. Thus, an increase in current income works like a relaxation of this (self-imposed) credit restriction. ${ }^{17}$ Households want to spend more on consumption, but they are not able to do so due to the riskiness of their expected income, thus every increase in income will be nearly totally consumed. Moreover, including the variance of future income makes the consumption function concave again, and not linear as in the neoclassical 
model.$^{18}$ Hence, the incorporation of a precautionary savings motive does not only lead to a higher MPC out of current income, but also to the dependence of the MPC on the income level. With increasing income levels, people tend to spend smaller fractions of their current income. To summarize, the precautionary savings model derives results that have been already stated by Keynes, namely a high MPC out of current income, and the concavity of the consumption function.

\section{Fundamental uncertainty in post-Keynesian consumption theory}

\section{I Assumptions}

Since consumption theory has been a neglected field in the post-Keynesian research program, in the following section, I will rely on the insights from Behavioral Economics and Economic Sociology. If consumers' choices are determined socially and made under fundamental uncertainty, households are limited in their ability to maximize utility, thus making it rational not to follow the optimization approach. Importantly, income is split into its different sources, arguing for different marginal propensities to consume out of labor income, profit income and financial income.

Furthermore, it is worth noting that now an intra-temporal model is considered. This stands in contrast to the typical concentration of neoclassical and New Keynesian theories of finding optimality conditions for several periods. This contrast results from the different role saving plays in the two paradigms. In the New Keynesian framework saving is merely postponed consumption, even if it results from precautionary motives. In the post-Keynesian approach however, in no way does saving signify consumption in a future period:

"An act of individual savings so to speak is a decision not to have dinner today. But it does not necessitate a decision to have a dinner or buy a pair of boots a week hence or a year hence or to consume any specified thing at any specified date. Thus it depresses the business of preparing today's dinner without stimulating the business of making ready for some future act of consumption [...] it is a net diminution of such demand." (Keynes 1936: 210)

This is the Keynesian paradox of thrift: Even if households wish to save more, the result can be the contrary. Macroeconomically, an increase in saving today leads to a lack of effective demand today with the actual saving being lower ex post than it should have been ex ante. Thus, the consumption model presented here stays in a one-period framework, and leaves questions about how aggregate saving affects output over time to growth theory. Consequently, expectations play no role in this model due to its one-period formulation. 


\subsection{The model}

To present a macroeconomic consumption function taking into account functional income distribution, one can proceed as follows. Households consume a fraction of their disposable income $Y^{D}$, which is total income $Y$ net of interest payments $i D$ plus new borrowing $B$ :

$$
C=c(Y-i D+B)
$$

As I have discussed above, the importance of disaggregating income into its different sources has recently been supported by Behavioral Economists. Using $Y=W+\Pi$, i.e., splitting total income into wage income $W$, and profit and financial income $\Pi$, the definition of the profit share $h=\Pi / Y$, and recalling that the marginal propensities to consume depend on the income source, one can specify equation (Io) further to get

$$
\begin{aligned}
C & =c_{W} W+c_{\Pi} \Pi+c_{B}[B-i D] \\
& =c_{W} Y+\left(c_{\Pi}-c_{W}\right) h Y+c_{B}[B-i D] \text {, with } c_{\Pi}, c_{W}, c_{B}<1 .
\end{aligned}
$$

Next, it is necessary to determine how much the consumer can borrow. Dutt (2006) and Bhaduri et al. (2006) have presented models of how to deal with the question of household borrowing and indebtedness in a post-Keynesian perspective. ${ }^{19}$ Dutt concentrates on distributional questions with workers financing a part of their consumption out of credit while having to pay interest to capitalists. On the other hand, Bhaduri et al. deal with the question of a »virtual wealth effect", i.e., how unrealized capital gains can be used to borrow more, and thus raise consumption above current income. Despite their different foci, both papers conclude that an increase in borrowing can boost consumption in the short run but has an ambiguous effect in the long run, depending on the indebtedness of households. To determine borrowing, I follow Dutt (2006), who adopted a flow formulation for the borrowing constraint, stating that borrowing is a function of households' total income minus their interest payments. Dealing with the effect of unrealized capital gains on borrowing, Bhaduri et al. (2006) use a stock formulation, assuming that borrowing is a decreasing function of the private sector's debt to income ratio for each level of virtual wealth. Since a discussion of asset price theories is far beyond the scope of this paper, I will leave out the question of unrealized capital gains. Note, however, that this could have been incorporated by simply adding virtual wealth in the borrowing constraint, or by letting $\beta$-the ratio of banks' lending practices and households borrowing propensity - depend on the level of asset prices. Here, borrowing is determined as

$$
B=\beta[Y-i D]
$$

and the consumption function (II) can be written as

$$
C=c_{W} Y+\left(c_{\Pi}-c_{W}\right) h Y+c_{B}[\beta Y-(1+\beta) i D]
$$


To evaluate the effects of changes in the level of income and in income distribution, and a loosening in lending practices, one can calculate the partial derivatives.

$$
\frac{\partial C}{\partial Y}=c_{W}+\left(c_{\Pi}-c_{W}\right) h+c_{B} \beta=(1-h) c_{W}+c_{\Pi} h+c_{B} \beta>0
$$

Ceteris paribus, an increase in the level of income raises consumption, whereas the effect is bigger the more income is distributed as wages, since $c_{W}>c_{\Pi}$-following the discussion above. In addition, implying rising creditworthiness of households, a rising income level also boosts consumption by inducing more borrowing. It is worth noting that the strength of this effect depends on the magnitude of $c_{B}$. Following Bhaduri et al. (2006), consumers borrow against "virtual wealth«, i.e. unrealized capital gains due to increased share prices. The mental account model suggests that the MPC out of future assets is virtually zero. However, one can argue that borrowing against unrealized capital gains relaxes this self-imposed restriction, since future asset income is transformed into current asset income, whose MPC is higher. In this light, $c_{B} \geq c_{\Pi}$. Next, a change in the income distribution towards a rise in the profit share lowers consumption:

$$
\frac{\partial C}{\partial h}=\left(c_{\Pi}-c_{W}\right) Y<0
$$

Finally, note that a rise of the creditworthiness of households increases consumption, as long as they are able to serve their interest payments out of their income. This rules out Ponzischemes: Even if households can temporarily borrow more than their disposable income, this cannot be possible forever.

$$
\frac{\partial C}{\partial \beta}=c_{B}[Y-i D]>0
$$

Fundamental uncertainty affects consumer decisions in two ways. Facing higher uncertainty about future income, households put more savings in liquid assets in order to be able to dissolve these savings without costs in future periods. Moreover, the marginal propensity to consume decreases if uncertainty rises, which gives the equivalent to the precautionary saving motive presented earlier.

\section{Conclusion: Similarities, differences, extensions}

To sum up - and to come back to the questions raised in the introduction - one can restate the following results. The enrichment of traditional neoclassical consumption theory with the New Keynesian precautionary savings approach can indeed be seen as a consensus model in the field of consumption theory. Consumers still maximize their utility over their lifetime and behave in the way of the rational choice theory, but the results turn out to be more Keynesian-like: One gets a high marginal propensity to consume out of current income, and the consumption function becomes concave, thus stressing again the role of personal income distribution. These results are similar to those pointed out by post-Key- 
nesians, and also by Behavioral Economists and Economic Sociologists. However, there remain several differences, namely the question of how to deal with uncertainty and functional distribution, leading to the following areas of future research:

First, it would be worth investigating the different model variants from an empirical perspective. Bagliano/Bertola (2004) state that the New Keynesian precautionary saving model can indeed explain some stylized facts in consumption behavior. Current income and consumption tend to move closely together, i.e. consumption is "excessively sensitive", and consumption is also found to be "excessively smooth «, i.e. consumers do not react strongly to unexpected income changes if this change is associated with higher uncertainty about future income. Whereas Reis (2006) claims that the sticky information model provides a better fit to the data than the precautionary saving approach, Branch (2007) states that model uncertainty is more valid from an empirical point of view. In order to clarify which kind of restriction really applies, more microeconometric research into the field of consumer decisions is needed.

Second, it is worth investigating the links between precautionary saving and growth theory. In standard neoclassical growth theory, higher uncertainty modeled as a higher variance of future income leads to more precautionary saving, which then increases the longrun growth rate. This implausible effect can only be cured when allowing for a second channel, as is the case in endogenous growth theory. ${ }^{20}$ Higher uncertainty induces firms to lower their spending for research and development, leading to a decrease of the long-run growth rate. Moreover, relaxing the neoclassical assumption of saving being causal for investment, Carroll et al. (2000) have proposed an alternative growth model in which precautionary saving could imply further negative effects on long-run growth. In this context, the role of institutions gains additional importance. Carlin/Soskice (2009) have argued that the labor market reforms in Germany during the last few years have had devastating effects on private consumption through confronting people with higher income uncertainty. This points to the need for policy makers to take into account the role of risk, uncertainty and social norms when implementing political reforms.

Third, including model uncertainty could provide a further way of dealing with the question of expectation formation under uncertainty in a New Keynesian framework. Miao (2004) has presented a model along this line, assuming that the consumer does not know the true probability distribution, but has to choose an appropriate distribution out of a probability set along the degree of uncertainty he attaches subjectively to each probability function. Assuming again that all probability functions are normally distributed, the consumption function (9) derived above is then transformed into

$$
C_{t}=\frac{R_{t}}{\left(1+R_{t}\right)}\left(Y_{t}+\mu_{Y}\right)-\frac{1}{\eta\left(1+R_{t}\right)} \ln R_{t} \beta-\frac{1}{\left(1+R_{t}\right)} \frac{1}{2} \eta^{2} \sigma_{Y}^{2}-\frac{1}{\left(1+R_{t}\right)} \sqrt{2} \phi \sigma_{Y}
$$

Here, the last term stands for precautionary saving due to (model) uncertainty that depends both on the parameter of uncertainty aversion $\phi$, and on the standard deviation of income 
$\sigma_{Y}$, in addition to the effect of the variance as in the standard precautionary saving model. Note that one could go even further: "The models presented here, though, do not allow for sticky information across competing models of the economy." (Branch 2007: 272)

Thus, it would be worth investigating whether such a specification could come closer to the Keynesian idea of fundamental uncertainty. It should be also investigated in more detail whether consumers form expectations in a different way than firms, and if so, what possible implications might arise from this.

Fourth, the role of the representative agent and its implications should be investigated in more detail. ${ }^{21}$ Remember that

"the reactions of the amount of his consumption on the income of others makes it impossible for all individuals simultaneously to save any given sums. Every [...] attempt to save more by reducing consumption will so affect incomes that the attempt necessarily defeats itself" (Keynes 1936: 84). ${ }^{22}$

It would be worth investigating this critique of the current-saving-equals-future-consumption statement in a New Keynesian framework, taking into account the arising discrepancies between microeconomic and macroeconomic logic. In models with heterogeneous agents, more attention should be paid to the social interaction of these agents, and to peer-groupdependent consumption behavior. This would also make it possible to discuss the effects of changes in the functional income distribution in more detail.

Finally, consumption theory should be seen in the light of recent developments in financial markets, and thus linked to the phenomenon of , financialization'. Since consumption theory in general is a neglected field in post-Keynesian theory, it is similarly neglected in the financialization literature. ${ }^{23}$ New Keynesian authors such as Galí et al. (2007) speculate that through higher asset market participation, aggregate consumption would get closer to the ideal optimizing and consumption smoothing model, thus arguing against the importance of their Keynesian-like rule-of-thumb consumer. However, both post-Keynesian and New Keynesian strands could come closer together in dealing with the impact of financial markets on consumption. If more people own financial assets they are confronted with additional risk by making their income more volatile, raising the question of an adequate policy under these conditions. At the same time, the incorporation of financial variables into post-Keynesian models makes the effects of interest changes on the goods-market-equilibrium ambiguous, thus pointing in the direction of New Keynesian approaches where consumption depends not only on current income, but also on wealth. A first model in this direction has recently been presented by Godley/Lavoie (2007).

23 See for an exception Ertük et al. (2005). 


\section{References}

Aghion, P., Howitt, P. (1997): Endogenous Growth Theory, Cambridge, Massachusetts: MIT Press.

Akerlof, G. (2007): The missing motivation in macroeconomics, in: American Economic Review, $97(\mathrm{I}), 5-36$.

Bagliano, F.-C., Bertola, G. (2004): Models for Dynamic Macroeconomics, Oxford: Oxford University Press.

Beckert, J. (1996): What is sociological about economic sociology? Uncertainty and the embeddedness of economic action, in: Theory and Society, 25, 803-840.

Bhaduri, A., Laski, K., Riese, M. (2006): A model of interaction between the virtual and the real economy, in: Metroeconomica, 57(3), 4I2 - 427.

Blanchard, O. (2009): (Nearly) nothing to fear but fear itself, in: The Economist, Vol. January 3Ist 2009.

Blanchard, O., Mankiw, G. (1988): Consumption: Beyond certainty equivalence, in: American Economic Review, 78(2), I73- I78.

Bourdieu, P. (1979): La Distinction, Critique Social du Jugement, Paris: Les Ed. de Minuit.

Boyer, R. (2000): Is a finance-led growth regime an alternative to Fordism? A preliminary analysis, in: Economy and Society, 29(I), III - I45.

Branch, W. (2007): Sticky information and model uncertainty in survey data on inflation expectations, in: Journal of Economic Dynamics and Control, 3I, 245-276.

Camerer, C., Loewenstein, G., Rabin, M. (2003): Advances in Behavioral Economics, Princeton: Princeton University Press.

Campbell, J., Mankiw, G. (1989): Consumption, income and interest rates: Reinterpreting the time series evidence, NBER Macroeconomic Annual, 4, I85-216.

Caplan, B. (2007): The Myth of the Rational Voter: Why Democracies Choose Bad Policies, Princeton: Princeton University Press.

Carlin, W., Soskice, D. (2009): German economic performance: Disentangling the role of supply-side reforms, in: Socio-Economic Review, 7, 67-99.

Carroll, C. (2000): Requiem of the representative consumer? Aggregate implications of microeconomic consumption behavior, in: American Economic Review, 90(2), IIO - II5.

Carroll, C. (200I): A theory of the consumption function. With and without liquidity constraints (expanded version), NBER Working Paper No. 8387.

Carroll, C. (2006): The epidemiology of macroeconomic expectations, in: Blume, L., Durlauf, S. (eds.), The Economy as an Evolving Complex System, III, Oxford: Oxford University Press, 5-30.

Carroll, C., Kimball, M. (1996): On the concavity of the consumption function, in: Econometrica, 64(4), 98I - 992.

Carroll, C., Kimball, M. (2008): Precautionary saving and precautionary wealth, in: Blume, L., Durlauf, S. (eds.), The New Palgrave Dictionary of Economics, $2^{\text {nd }}$ Edition, London: Palgrave Macmillan, 579-585. 
Carroll, C., Overland, J., Weil, D. (2000): Saving and growth with habit formation, in: American Economic Review, 90(3), 34I - 355.

Davidson, P. (I99I): Is Probability Theory relevant for uncertainty? A post-Keynesian perspective, in: Journal of Economic Perspectives, 5(I), I29 - I43.

Duesenberry, J. (1949): Income, Saving and the Theory of Consumer Behavior, Cambridge, Massachusetts: Harvard University Press.

Dutt, A.K. (2006): Maturity, stagnation and consumer debt: A Steindlian approach, in: Metroeconomica, 57(3), $339-364$.

Ertük, I., Froud, J., Solari, S., Williams, K. (2005): The reinvention of prudence: Household savings, financialisation and forms of capitalism, CRESC Working Paper, No. II.

Falk, A., Knell, M. (2004): Choosing the Joneses: Endogenous goals and reference standards, in: Scandinavian Journal of Economics, I06(3), 4I7 - 435.

Fontana, G., Gerrard, B. (2004): A post-Keynesian theory of decision making under uncertainty, in: Journal of Economic Psychology, 25, 619- 637.

Friedman, M. (1957): A Theory of the Consumption Function, Princeton: Princeton University Press.

Galbraith, J.K. (1958): The Affluent Society, Harmondsworth: Penguin.

Galí, J., Vallés, J., López-Salido, J.D. (2007): Understanding the effect of government spending on consumption, in: Journal of the European Economic Association, 5(I), 227 - 270.

Geanakoplos, J., Pearce, D., Stacchetti, E. (1989): Psychological games and sequential rationality, in: Games and Economic Behaviour, I(I), $60-79$.

Gertchev, N. (2007): A critique of adaptive and rational expectations, in: Quarterly Journal of Austrian Economics, IO, 313-329.

Glaeser, E., Scheinkman, J., Sacerdote, B. (2003): The social multiplier, in: Journal of the European Economic Association, I(2/3), 345 - 353.

Godley, W., Lavoie, M. (2007): Monetary Economics: An Integrated Approach to Credit, Money, Income, Production and Wealth, London: Palgrave Macmillan.

Größl, I., Fritsche, U. (2007): The store-of-value-function of money as a component of household risk management, DEP Discussion Papers No. 6/2007.

Hall, R. (1978): Stochastic implications of the life-cycle-permanent-income hypothesis: Theory and evidence, in: Journal of Political Economy, 86(6), 97I - 987.

Hansen, L.P., Sargent, T. (2007): Robustness, Princeton: Princeton University Press.

Hein, E. (2004): Verteilung und Wachstum, Marburg.

Hein, E. (2005): Reale und monetäre Analyse: Post-Keynesianismus und Neu-Keynesianismus im Vergleich, in: Hein, E., Heise, A., Truger, A. (eds.), Neu-Keynesianismus: Der neue wirtschaftspolitische Mainstream?, Marburg: Metropolis.

Heiner, R. (1983): The origin of predictable behavior, in: American Economic Review, 73(4), 560 -595 .

Holländer, H. (200I): On the validity of utility statements: Standard theory versus Duesenberry's, in: Journal of Economic Behavior and Organization, 45, 227 - 249.

Horkheimer, M., Adorno, T. (1947): Dialektik der Aufklärung: Philosophische Fragmente, Frankfurt a.M.. 
Kahnemann, D., Thaler, R. (2006): Utility maximization and experienced utility, in: Journal of Economic Perspectives, 20(I), 22I - 234.

Keynes, J.M. (1936): The General Theory of Employment, Interest and Money, Hampshire and New York: Palgrave Macmillan.

Keynes, J.M. (1937): The General Theory of employment, in: Quarterly Journal of Economics, 5I(2), $209-223$.

Kimball, M. (I990): Precautionary saving in the small and in the large, in: Econometrica, 58(I), $53-73$.

Knight, F. (I92I): Risk, Uncertainty and Profit, Boston: Houghton Mifflin.

Lavoie, M. (1994): A post-Keynesian theory of consumer choice, in: Journal of Post-Keynesian Economics, I6(4), $539-562$.

Lavoie, M. (2004): Post-Keynesian consumer theory: Potential synergies with consumer research and economic psychology, in: Journal of Economic Psychology, 25, 639-649.

Lawson, T. (1988): Probability and uncertainty in economic analysis, in: Journal of Post-Keynesian Economics, II(I), 38 - 65 .

Lucas, R. (1972): Expectations and the neutrality of money, in: Journal of Economic Theory, 4, IO3 - I24.

Luhmann, N. (1984): Soziale Systeme: Grundriss einer allgemeinen Theorie, Frankfurt a.M.

Mas-Colell, A., Whinston, M., Green, J. (1995): Microeconomic Theory, Oxford: Oxford University Press.

Maslow, A. (1943): A theory of human motivation, in: Psychological Review, 50, $370-396$.

Miao, J. (2004): A note on consumption and savings under Knightian uncertainty, in: Annals of Economics and Finance, 5, 299 - 3II.

Modigliani, F., Brumbergh, R. (1954): Utility analysis and the consumption function: An interpretation of cross-section data, in: Kurihara, K. (ed.), Post-Keynesian Economics, New Brunswick: Rutgers University Press.

Muchlinski, E. (1996): Keynes als Philosoph, Berlin: Humblot und Duncker.

Muth, J. (196I): Rational expectations and the theory of price movements, in: Econometrica, 29(3), $315-335$.

Reis, R. (2006): Inattentive consumers, in: Journal of Monetary Economics, 53, I76I - I800.

Rosser, J.B. (200I): Alternative Keynesian and post-Keynesian perspectives on uncertainty and expectations, in: Journal of Post-Keynesian Economics, 23(4), 545- 566.

Rudd, J., Whelan, K. (2006): Can Rational Expectations Sticky-Price Models explain inflation dynamics?, in: American Economic Review, 96(I), 303-320.

Shackle, G.L.S. (1955): Uncertainty in Economics and Other Reflections, Cambridge: Cambridge University Press.

Shefrin, H., Thaler, R. (1988): The behavioral Life-Cycle Hypothesis, in: Economic Inquiry, 26(4), $609-643$.

Sims, C. (2003): Implications of rational inattention, in: Journal of Monetary Economics, 50(3), $665-690$.

Sobel, J. (2005): Interdependent preferences and reciprocity, in: Journal of Economic Literature, $43(2), 392-436$. 
Trigg, A. (2004): Deriving the Engel Curve: Pierre Bourdieu and the social critique of Maslow's Hierarchy of Needs, in: Review of Social Economy, 62(3), 393- 406.

Woodford, M. (1990): Learning to believe in sunspots, in: Econometrica, 58(2), 277 - 307.

Zukin, S. (2006): Consumption, in: Beckert, J., Zafirovski, M. (eds.), International Encyclopedia of Economic Sociology, IOI - IO7, London: Routledge. 